\title{
Effects of Landfill Gas Flow Trajectories at Three Distinct Temperature Phases on the Stress-Strain-Displacement Properties of a Gas Extraction Pipe
}

\author{
${ }^{* 1}$ ORHORHORO; EK, ${ }^{2}$ IKPE AE; ${ }^{3}$ UKWABA, SI \\ ${ }^{* 1}$ Department of Mechanical Engineering, Igbinedion University, Okada, Nigeria \\ *Corresponding Author Email: ejiroghene.orhorhoro@iuokada.edu.ng; Tel: +2348064699781 \\ ${ }^{2}$ Department of Mechanical Engineering, University of Benin, Benin City, Nigeria. \\ Email:ikpeaniekan@gmail.com \\ ${ }^{3}$ Department of Mechanical Engineering, Petroleum Training Institute, Effurun, Nigeria \\ Email:ukwuaba@yahoo.com
}

\begin{abstract}
The rate of MSW generation is increasing and at present, there is no single engineered landfill designed to address the challenges posed by MSW generation in Nigeria. Unmanaged open dump sites and uncontrolled MSW disposal is currently practiced in Nigeria, thus this research work which is focused on the effects of landfill gas flow trajectories at three distinct temperature phases on the stress-strain-displacement properties of a gas extraction. Conservation mass equation was derived for solid, liquid, and gaseous phase. A PVC plastic with a linear elastic isotropic property was used. Von Mises Stress was used as the default failure criterion. The material yield and tensile strength were $52 \mathrm{~N} / \mathrm{mm}^{\wedge} 2$ and $30 \mathrm{~N} / \mathrm{mm}^{\wedge} 2$. Other properties of the material include; elastic modulus of $3000 \mathrm{~N} / \mathrm{mm}^{\wedge} 2$, poisson's ratio of 0.394 , mass density of $1020 \mathrm{~g} / \mathrm{cm}^{\wedge} 3$, shear modulus of $318.9 \mathrm{~N} / \mathrm{mm}^{\wedge} 2$, and thermal expansion coefficient of $79 / \mathrm{K}$. The results obtained reveal that the rate of gas generation in a landfill is dependent on the increase in temperature and pressure within the landfill system, usually causing subsurface pressures in the landfill to be higher than either the atmospheric pressure or indoor air pressure.
\end{abstract}

\section{DOI: https://dx.doi.org/10.4314/jasem.v22i11.5}

Copyright: Copyright $\left({ }^{\circ} 2018\right.$ Orhorhoro et al. This is an open access article distributed under the Creative Commons Attribution License (CCL), which permits unrestricted use, distribution, and reproduction in any medium, provided the original work is properly cited.

Dates: Received: 07 September 2018; Revised: 02 October 2018; Accepted 1 November 2018

Keywords: Landfill, Gas flow trajectory, temperature, pressure, PVC plastic, open dump site

Solid waste generation is one of the most significant environmental challenges bedevilling Nigerian cities and the wellbeing of its inhabitants (Orhorhoro et al., 2017). Although solid waste is an asset when properly managed, the rate at which solid waste is generated in Nigeria is increasing tremendously in recent times as a result of population growth, consumption rate, industrialisation, socioeconomic development etc. (Aluko et al., 2003; Orhorhoro et al., 2017). Nigeria is the $6^{\text {th }}$ most populous country in the world with estimated population of about 180 million (World Population Review, 2015) and since rapid human population growth is a key factor influencing the rate of waste generation, Nigeria is not an exception. For example, Adewumi et al. (2005) reported that over $0.58 \mathrm{~kg}$ of solid waste is generated per person per day in Nigeria. Going by this figure, the total amount of waste generated daily in Nigeria can be estimated at about 103,240,000 kg/day (103,240 tonnes/day). In addition, Ogwueleka (2009) reported that more than 25 million tonnes of solid waste is generated annually in Nigeria, with average rate of generation ranging from $0.44 \mathrm{~kg} / \mathrm{cap} /$ day in rural areas to $0.66 \mathrm{~kg} / \mathrm{cap} / \mathrm{d}$ in urban areas. According to Lijun et al. (2014), biogas is a type of gas that is generated in an open or close system, through fermentation and breakdown of biodegradable or organic matter by anaerobic bacteria in the absence of oxygen. It contains 30-68\% Methane $\left(\mathrm{CH}_{4}\right), 30-40 \%$ of Carbon dioxide $\left(\mathrm{CO}_{2}\right)$ and $2-10 \%$ traces of moisture, elements and chemical compounds such as Hydrogen Sulphide $\left(\mathrm{H}_{2} \mathrm{~S}\right)$, Siloxane, Hydrogen $\left(\mathrm{H}_{2}\right)$ etc.(Orhorhoro et al., 2018). Although $\mathrm{CO}_{2}$ has zero heating value for combustion in air/oxygen, biogas is still a high-quality fuel gas due to methane content which can be as high as $70 \%$ in biogas produced from municipal solid wastes, making biogas a potential energy source for household consumption (Tester et al., 2005; Olmedo et al., 2014). Moreover, methane and hydrogen can be subjected to combustion or oxidized with oxygen to generate energy, which enables the use of biogas as fuel in turbines, domestic stoves and IC engines. Besides, methane is highly poisonous in the atmosphere and contributes to global warming as it is a major Green House Gas (GHG) that is 21 times more potent than $\mathrm{CO}_{2}$ when released into the atmosphere (Seadi et al., 2008; Rawson et al., 2012; Arnold, 2009). On the basis of the aforementioned point of view, there is need for 
transformational conversion of waste dumpsites in Nigeria into proper landfills through the use of current landfill technology.

However, with the growing population of people residing in Nigeria, the rate of MSW generation is increasing and there is no single engineered landfill designed to address the challenges posed by MSW generation in Nigeria (Ukwaba et al., 2018). Hence, it is obvious that open landfills, unmanaged dump sites and uncontrolled MSW disposal is currently practiced as a major economic waste disposal option in Nigeria, and designing a landfill system in the course of this study will aid in the minimisation of GHG emissions, protection of soil and ground water from being contaminated by leachate from open dumpsites and will also generate a cheap renewable energy resource (biogas) to meet the rising energy demand in Nigeria. Immediately after final capping of the landfill, it becomes difficult to determine the chemical reactions in terms of velocity of liquid and gas as well of the relative rate of decomposition of organic feedstock in the system (Durmusoglu et al., 2005). However, the landfill chemistry is assumed to comprise of three (3) phases such as the solid phase in terms of MSW buried within the landfill system, liquid phase in terms of leachate generation and the gas phase which is the landfill gas generation, with both the liquid and gas phases assumed to be compressible and the solid phase classified into organic and inorganic MSW materials. However, this study is limited to the organic fraction of MSW.

\section{MATERIALS AND METHODS}

Conservation of Mass Equation for the Solid Phase: The solid phase is comprised of organic and inorganic waste fractions with density of the inorganic component of MSW assumed to be constant in space and time, of which the conservation of mass equation for the solid phase is given by Equation (1);

$-\frac{\partial \rho_{b}}{\partial t}=\frac{\partial\left(\rho_{b} V_{S}\right)}{\partial z}+\alpha_{T} Y$

Where, $p_{b}=$ Bulk density of solid waste; $V s=$ Solid phase velocity; $Y=$ Yield coefficient (mass of solid waste/mass of gas phase); and $z=$ Spatial coordinate.

As the organic fraction of the landfilled waste substrate diminishes with time, the inorganic fraction approaches one (that is, $s_{o}+s_{i}=1$ ). This is given by Equation (2) and Equation (3);

$$
\begin{aligned}
& -\frac{\partial\left[(1-n) s_{o} \rho_{o}\right]}{\partial t}=\frac{\partial\left[(1-n) s_{o} \rho_{o} V_{S}\right]}{\partial z}+\alpha_{T} \\
& -\frac{\partial\left[(1-n) s_{i} \rho_{i}\right]}{\partial t}=\frac{\partial\left[(1-n) s_{i} \rho_{i} V_{S}\right]}{\partial z}+\alpha_{T} Y
\end{aligned}
$$

Where, $n=$ Porosity of waste fraction; so = Organic fraction of solid waste; $s_{i}=$ Inorganic fraction of the solid waste $; p_{o}=$ Density of organic fraction of solid waste and $p_{i}=$ Density of inorganic portion of solid waste.

The sum of the organic and inorganic portions gives the total bulk density of MSW expressed by Equation (4);

$\rho_{b}=(1-n)\left(s_{o} \rho_{o}+s_{i} \rho_{i}\right)$

Conservation of mass for the Liquid Phase: The conservation of mass for the liquid phase is expressed as by Equation (5a);

$-\frac{\partial\left(\rho_{l} \theta_{l}\right)}{\partial t}=\frac{\partial\left(\rho_{l} \theta_{l} V_{l}\right)}{\partial z}$

Where, $p_{l}=$ Liquid phase density; $\theta_{l}=$ Volumetric liquid content expressed as $\theta_{l}=n S_{l} ; S_{l}=$ Liquid phase saturation; $V_{l}=$ liquid phase velocity.

However in a deforming porous medium, the solid particles, as well as the liquid and gas phases are in motion. Given by Equation (5b), Darcy's law can be expressed in terms of the liquid velocity relative to the deforming solid phase;

$q_{r l}=-\frac{k_{r l} k}{\mu_{1}}\left(\frac{\partial P_{l}}{\partial z}-\rho_{l} g\right)=\theta_{l}\left(V_{l}-V_{s}\right)$

Where, $q_{r l}=$ Specific liquid discharge relative to moving solid; $k=$ Permeability; $k_{r l}=$ Relative permeability of the liquid phase $P_{l}=$ Liquid pressure; $\mu_{i}=$ Viscosity of the liquid phase and $\mathrm{g}=$ Acceleration due to gravity.

The compressibility of the liquid phase $\beta_{l}$, is defined under isothermal condition as shown in Equation (6);

$\beta_{l}=\frac{1}{\mathrm{p}_{l}} \frac{\partial \rho_{l}}{\partial \rho_{l}}$

Integrating Equation (6) gives the equation of state for the liquid phase

$$
\rho_{l}=\rho_{l}^{o} \exp \left[\beta_{l}\left(P_{l}-P_{l}^{o}\right)\right]
$$

Where, $\rho_{l}^{o}=$ Initial liquid density and $P_{l}^{o}=$ Reference liquid pressure.

Equation (7) can approximately be written as;

$\rho_{l}=\rho_{l}^{o}\left[1+\beta_{l}\left(P_{l}-P_{l}^{o}\right)\right]$

For incompressible liquids, $\beta_{l}=0$ and $\rho_{l}=\rho_{l}^{o}=$ Constant. 
Estimating the liquid content in terms of leachate generation in an active landfill, the equation is given by;

$L_{A}=P+S-E-W A$

Where, $\mathrm{L}_{\mathrm{A}}=$ Leachate from active area, $\mathrm{P}=$ Precipitation, $\mathrm{S}=$ Pore squeeze liquid from waste, $\mathrm{E}=$ Evaporation, $W A=$ Waste moisture absorption.

Conservation of Mass Equation for the Gas Phase: The conservation of mass equation for the gas phase is given by Equation (10).

$-\frac{\partial\left(\rho_{g} \theta_{g}\right)}{\partial t}=\frac{\partial\left(\rho_{g} \theta_{g} V_{g}\right)}{\partial z}-\alpha_{T}$

Where, $\rho_{g}=$ Gas mixture density; $\theta_{g}=$ Volumetric gas content expressed as $\theta_{g}=n S_{g} ; S_{g}=$ Gas phase saturation, and $V_{g}=$ Gas phase velocity.

Similar to the liquid phase, the velocity of the gas phase relative to the deforming solid phase is expressed by Equation (11);

$q_{r g}=-\frac{k_{r g} k}{\mu_{g}}\left(\frac{\partial P_{g}}{\partial z}-\rho_{g} g\right)=\theta_{g}\left(V_{g}-V_{s}\right)$

Where, $q_{r g}=$ Specific gas discharge relative to moving solid; $k_{r g}=$ Relative permeability of the gas phase $P_{g}=$ Gas pressure, and $\mu_{g}=$ Viscosity of the gas phase.

The equation of state for the gas phase is expressed by the ideal gas law expressed by Equation (12);

$$
P_{g}=\frac{\rho_{g}}{M_{g}} \bar{R} \phi
$$

Where, $M g=$ Molecular weight of gas mixture; $\bar{R}=$ Universal gas constant and $\Phi=$ Absolute temperature.

Under isothermal conditions, Equation (12) can be expressed as shown in Equation (13)

$\frac{d \rho_{g}}{d \rho_{g}}=\rho_{g}^{O} \frac{1}{P_{g}^{O}}$

Where, $\rho_{g}^{O}=$ Initial gas mixture density and $P_{g}^{O}=$ Reference gas pressure. Equation (13) can further be expressed as shown in Equation (14);

$\rho_{g}=\rho_{g}^{O} \frac{P_{g}}{P_{g}^{O}}$

The density and the molecular weight of the gas mixture can be estimated by using Equation (15) $\rho_{g}=\sum_{i} y_{i} \rho_{g}^{i},=1,2 \quad$ (15) and

$M_{g}=y_{i} M_{i}+y_{j} M_{j}$

Where, $\rho_{g}^{i}=$ Gas density $\left(i ; y_{i}\right), y_{j}=$ Mole fractions of the gas, $M_{i}$, and $M_{j}$ is the molecular weights of the gas.

Viscosity of the gas mixture can be expressed as a function of the viscosities of individual gases (Reid et al. 1987), given by Equation (17);

$\varphi_{i j}=\frac{\left[1+\left(\frac{\mu_{i}}{\mu_{j}}\right)^{1 / 2}\left(\frac{M_{j}}{M_{i}}\right)^{1 / 4}\right]^{2}}{\sqrt{8}\left(1+\frac{M_{i}}{M_{j}}\right)^{1 / 2}}$

Where $\mu_{i}$ and $\mu_{j}$ is equal to viscosities of the gas. Municipal solid waste is a porous medium with pore spaces between irregularly shaped solid grains. However, due to the lack of an expression relating the permeability to the properties of MSW, and being one of the most widely used expressions (Bear 1972), the Kozeny-Carman equation is employed as shown in Equation (18);

$k=k_{o} \frac{n^{3}}{(1-n)^{2}}$

Where, $k_{o}=$ reference permeability

Since the voids in MSW are not completely filled by the liquid phase, the presence of the gas phase reduces the volume of medium available for liquid flow in an unsaturated medium. When the gas and liquid phases flow together through a porous medium, saturations of the phases are less than unity $\left(S_{l}+S_{g}=1\right)$. The relative permeability of some materials such as MSW is difficult to predict due its non-uniform and volatile properties. However, Brooks and Corey (1966) proposed the possible relationships for relative permeability of MSW as;

$\begin{aligned} k_{r l} & =\frac{k_{l}}{k}=\left(\frac{S_{l}-S_{r}}{s_{m}-S_{r}}\right)^{3} \\ k_{r g} & =\frac{k_{g}}{k}=\left(1-\frac{S_{l}-S_{r}}{s_{m}-S_{r}}\right)^{3}\end{aligned}$

Where, $k_{l}=$ Permeability of liquid phase; $k_{g}=$ Permeability of gas phase; $S_{r}=$ Residual saturation and $S_{m}=$ Maximum saturation.

Durmusoglu (2002) expressed the mass balance equation for the liquid and gas phase relation given by Equation (21) and (22). 


$$
n S_{l} \rho_{l} \beta \frac{\partial P_{l}}{\partial t}+\rho_{l} n \frac{\partial S_{l}}{\partial t}+\rho_{l} S_{l} \frac{\partial V_{s}}{\partial z}+\rho_{l} S_{l} \frac{\alpha^{*} Y}{\rho_{s}}=\frac{\partial}{\partial z}\left[\frac{\rho_{l} k_{l}}{\mu_{l}}\left(\frac{\partial \rho_{l}}{\partial z}-\rho_{l} g\right)\right]
$$

And,

$$
n\left(1-S_{l}\right) \frac{\bar{M}}{\bar{R} \phi} \frac{\partial P_{g}}{\partial t}-\rho_{g} n \frac{\partial S_{l}}{\partial t}+\rho_{g}\left(1-S_{l}\right) \frac{\partial V_{s}}{\partial z}+\alpha^{*}\left(\frac{Y \rho_{g}\left(1-S_{l}\right)}{\rho_{s}}-1\right)=\frac{\partial}{\partial z}\left[\frac{\rho_{g} k_{g}}{\mu_{g}}\left(\frac{\partial P_{g}}{\partial z}-\rho_{g} g\right)\right]
$$

The materials properties is presented in Table 1

\begin{tabular}{|c|c|c|}
\hline Name: & \multicolumn{2}{|c|}{ PVC plasticised } \\
\hline Model type: & \multicolumn{2}{|c|}{ Linear Elastic Isotropic } \\
\hline Default failure criterion: & \multicolumn{2}{|c|}{ Max von Mises Stress } \\
\hline Yield strength: & \multicolumn{2}{|c|}{$52 \mathrm{~N} / \mathrm{mm}^{\wedge} 2$} \\
\hline Tensile strength: & \multicolumn{2}{|c|}{$30 \mathrm{~N} / \mathrm{mm}^{\wedge} 2$} \\
\hline Elastic modulus: & \multicolumn{2}{|c|}{$3000 \mathrm{~N} / \mathrm{mm}^{\wedge} 2$} \\
\hline Poisson's ratio: & \multicolumn{2}{|c|}{0.394} \\
\hline Mass density: & \multicolumn{2}{|c|}{$1020 \mathrm{~g} / \mathrm{cm}^{\wedge} 3$} \\
\hline Shear modulus: & \multicolumn{2}{|c|}{$318.9 \mathrm{~N} / \mathrm{mm}^{\wedge} 2$} \\
\hline Thermal expansion coefficient: & \multicolumn{2}{|c|}{79 /Kelvin } \\
\hline \multicolumn{3}{|c|}{ The mesh information is shown in Table 2} \\
\hline \multicolumn{3}{|c|}{ Table 2: Mesh Information } \\
\hline Total Nodes & & 56671 \\
\hline Total Elements & & 28537 \\
\hline Maximum Aspect Ratio & & 18.343 \\
\hline$\%$ of elements with Aspect Ratio & & 94.3 \\
\hline$\%$ of elements with Aspect Ratio & $>10$ & 0.154 \\
\hline Mesh InformationMesh type & & Solid Mesh \\
\hline Mesher Used: & & $\begin{array}{l}\text { Curvature } \\
\text { based mesh }\end{array}$ \\
\hline Jacobian points & & 4 Points \\
\hline Maximum element size & & $7.19498 \mathrm{~mm}$ \\
\hline Minimum element size & & $2.3983 \mathrm{~mm}$ \\
\hline Mesh Quality & & High \\
\hline
\end{tabular}

Table 1: Materials Properties

Fig 1 shows the simulated gas extraction pipe using Solid Work.

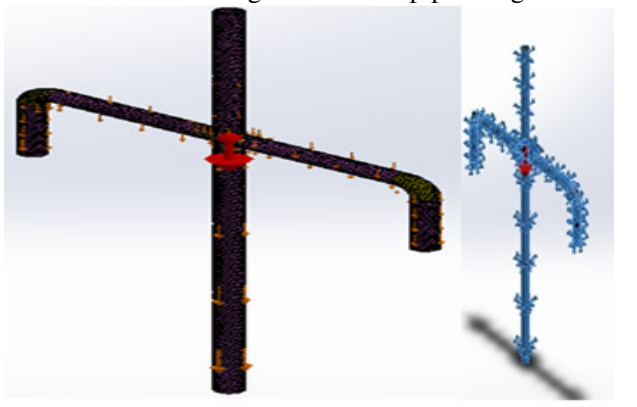

Fig. 1: Simulated Gas Extraction Pipe using Solid Work

The boundary conditions are shown in Table 3 to Table 5 .

Table 3: Inlet Volume Flow

\begin{tabular}{ll} 
& Table 3: Inlet Volume Flow \\
\hline Type & Inlet Volume Flow \\
\hline Faces & Face<7>@ @ID6-2 \\
Flow parameters & $\begin{array}{l}\text { Flow vectors direction: Normal to face } \\
\text { Volume flow rate: } 0.1000 \mathrm{~m}^{\wedge} 3 / \mathrm{s}\end{array}$ \\
Thermodynamic & Approximate pressure: $101325.00 \mathrm{~Pa}$ \\
parameters & Temperature: $293.20 \mathrm{~K}$ \\
\hline
\end{tabular}

Table 4: Total Pressure

\begin{tabular}{|c|c|}
\hline $\begin{array}{l}\text { Thermodynamic } \\
\text { parameters }\end{array}$ & $\begin{array}{l}\text { Face }<10>@ \text { Pipe_1^Assem1-1/straight } \\
\text { cross inch-1 } \\
\text { Total Pressure: } 500000.00 \mathrm{~Pa} \\
\text { Temperature: } 293.20 \mathrm{~K}\end{array}$ \\
\hline \multicolumn{2}{|r|}{ Table 5: Outlet Volume Flow 1} \\
\hline Type & Outlet Volume Flow \\
\hline Faces & Face $<6>@$ LID5-1 \\
\hline Flow parameters & $\begin{array}{l}\text { Flow vectors direction: Normal to face } \\
\text { Volume flow rate: } 1.0000 \mathrm{~m}^{\wedge} 3 / \mathrm{s}\end{array}$ \\
\hline
\end{tabular}

\begin{tabular}{ll}
\hline Type & Total pressure \\
\hline Faces & Face $<8>@$ Pipe_1^Assem1-1/straight \\
& cross inch-1 Face $<9>@$ Pipe_1^Assem1- \\
& 1/1inSchedule40^Pipe_1_Assem1-1 \\
\hline
\end{tabular}

\section{RESULTS AND DISCUSSION}

The results of minimum and maximum landfill gas parameters are shown in Table 6 . The results revealed a minimum pressure of $18781.47 \mathrm{~Pa}$, minimum fluid temperature of $126.96 \mathrm{~K}$, minimum density fluid of $0.28 \mathrm{~kg} / \mathrm{m}^{3}$, minimum velocity of $-195.020 \mathrm{~m} / \mathrm{s}$ (Xaxis), -28.893 (Y-axis), -201.483 (Z-axis), minimum vorticity of $22.226 \mathrm{l} / \mathrm{s}$, minimum shear stress of 0 , minimum relative pressure $-82543.53 \mathrm{~Pa}$. However, for the maximum values; the pressure, fluid temperature, density of fluid, velocity in XYZ axis, vorticity, shear stress, and relative pressure were obtained as $507113.54 \mathrm{~Pa}, 302.20 \mathrm{~K}, 3.34 \mathrm{k} / \mathrm{m}^{3}$, $2198.108 \mathrm{~m} / \mathrm{s}, 195.130 \mathrm{~m} / \mathrm{s}$ 9X-axis), 2197.940 (Yaxis), 202.130 (Z-axis), $71927.174 \mathrm{l} / \mathrm{s}, 411.08 \mathrm{~Pa}$, and 405788.54 Pa.

Table 6: Min/Max Table

\begin{tabular}{lll}
\hline Landfill gas parameters & & \\
\hline Name & Minimum & Maximum \\
Pressure (Pa) & 18781.47 & 507113.54 \\
Density Fluid $\left(\mathrm{kg} / \mathrm{m}^{\wedge} 3\right)$ & 0.28 & 3.34 \\
Velocity (m/s) & 0 & 2198.108 \\
Velocity (X) (m/s) & -195.020 & 195.130 \\
Velocity (Y) (m/s) & -28.893 & 2197.940 \\
Velocity (Z) (m/s) & -201.483 & 202.130 \\
Temperature (Fluid) (K) & 126.96 & 302.20 \\
Mach Number & 0 & 7.23 \\
Vorticity (1/s) & 22.226 & 71927.174 \\
Shear Stress (Pa) & 0 & 411.08 \\
Relative Pressure (Pa) & -82543.53 & 405788.54 \\
Heat Transfer Coefficient & 0 & 0 \\
(W/m^2/K) & & \\
Surface Heat Flux & 0 & 0 \\
(W/m^2) & & \\
\hline
\end{tabular}

The pressure flow trajectory in Fig. 2 was derived from mesophilic temperature distribution shown in Fig. 4. Variation in pressure within the landfill system resulted from the movement of gases from a region of high pressure to regions of low pressure, a phenomenon known as convection. Therefore, accumulation of gases in a landfill system can create domains for high pressure build-ups where gas 
migration is impeded by compacted waste stream or landfill covers and areas of low pressure in which gas flow is not restricted, thereby causing the movement of gases from areas of high gas concentrations to areas with lower gas concentrations.

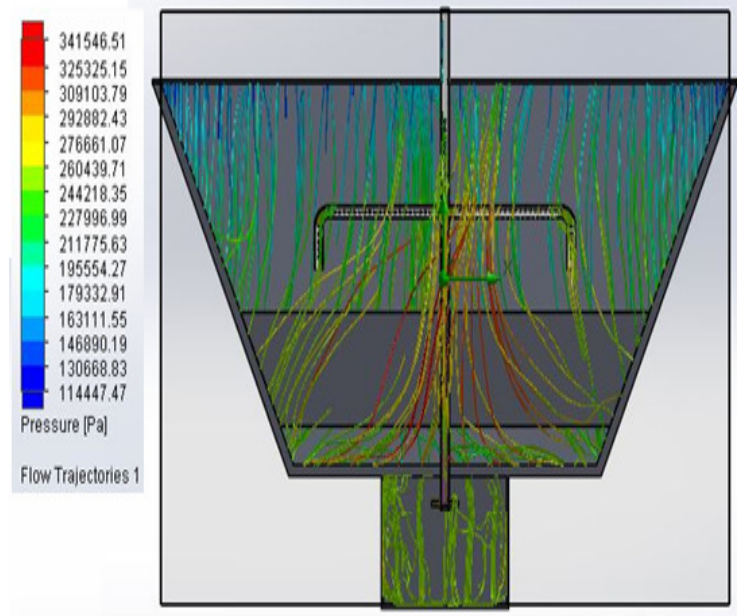

Fig. 2: Pressure Flow Trajectory within the Landfill System

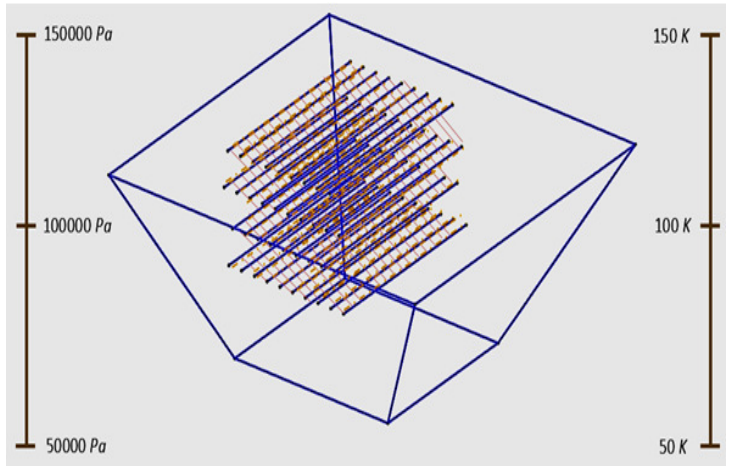

Fig. 3: Pressure Distribution at Cryophilic Temperature Range $(50 \mathrm{k}-150 \mathrm{k})$

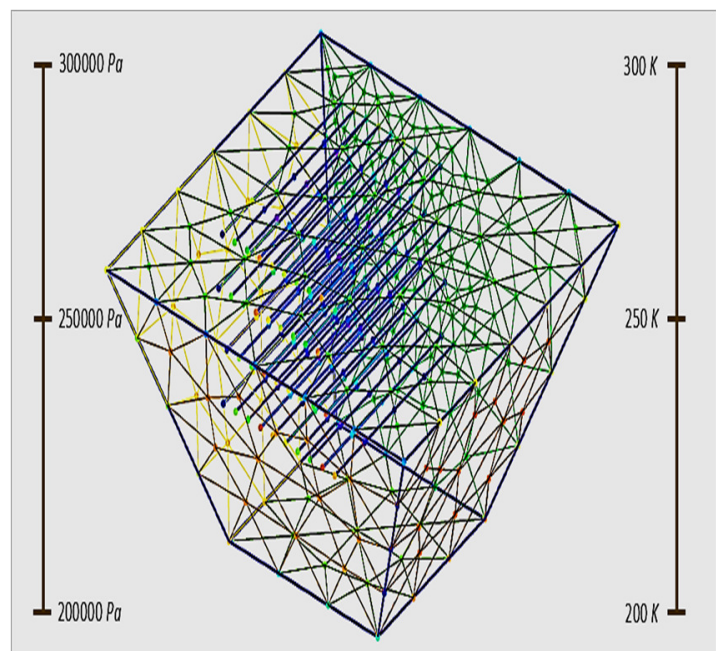

Fig. 4: Pressure Distribution at Mesophilic Temperature Range 200k-300k

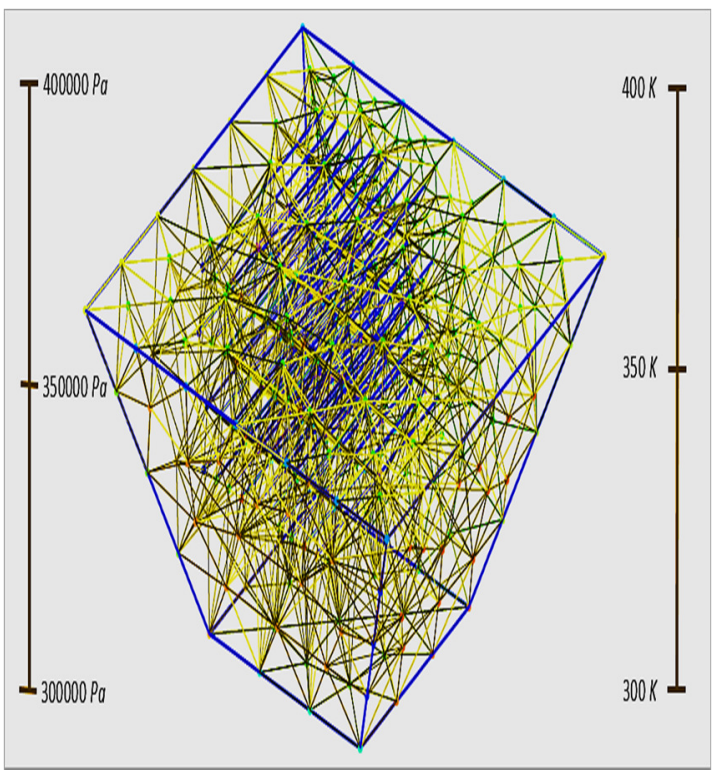

Fig. 5: Pressure Distribution at Thermophilic Temperature Range (300k-400k)

The red colour on the colour chart in Fig. 2, best describes this condition in which the pressure at the bottom of the landfill (about $300000 \mathrm{~Pa}$ ) within the compacted porous layers tends to be higher, but later reduce to about 1 bar at the topmost part of the landfill where gas flow is not restricted. However, the rate of gas generation in a landfill is dependent on the increase in temperature and pressure within the landfill system, usually causing subsurface pressures in the landfill to be higher than either the atmospheric pressure or indoor air pressure. Fig. 3-5 describes the pressure distribution network at certain Cryophilic, Mesophilic and Thermophilic Temperatures differential.

The results from the flow simulation were used to perform a stress analysis in order to check the stresses due to the flow effects. A fluid pressure effect from SolidWorks flow simulation was applied and gravity of $9.806 \mathrm{~m} / \mathrm{s}^{2}$ was applied vertically downwards and the resultant force in the $\mathrm{X}, \mathrm{Y}$ and $\mathrm{Z}$ direction as presented in Table (7). The Von Mises Yield Stress (Fig. 6) revealed that the system is safe and possible failure will not occur. Fig. 7 and Fig. 8 show the damage percentage and total life cycle. It was observed that the lower the stress applied, the greater the number of cycle to failure and vice-versa. Besides, at the endurance limit or fatigue limit, the SN curve flattens at $10 \mathrm{e} 6$ cycle. Thus, stress below the fatigue limit can be applied repeatedly in an indefinite number of times without causing any significant failure. Hence, the system is safe. 
Table 7: Pressure Induced Forces on the Gas Extraction Pipe

\begin{tabular}{llllllll}
\multicolumn{8}{c}{ Table 7: Pressure Induced Forces on the Gas Extraction Pipe } \\
\cline { 3 - 8 } Reaction & Selection set & Units & Sum X & Sum Y & Sum Z & Resultant \\
\cline { 2 - 8 } Forces & Entire Model & N & 203223 & 87095.5 & -10675 & 221358 \\
Reaction & Selection set & Units & Sum X & Sum Y & Sum Z & Resultant \\
Moments & Entire Model & N.m & 0 & 0 & 0 & 0 \\
\hline
\end{tabular}

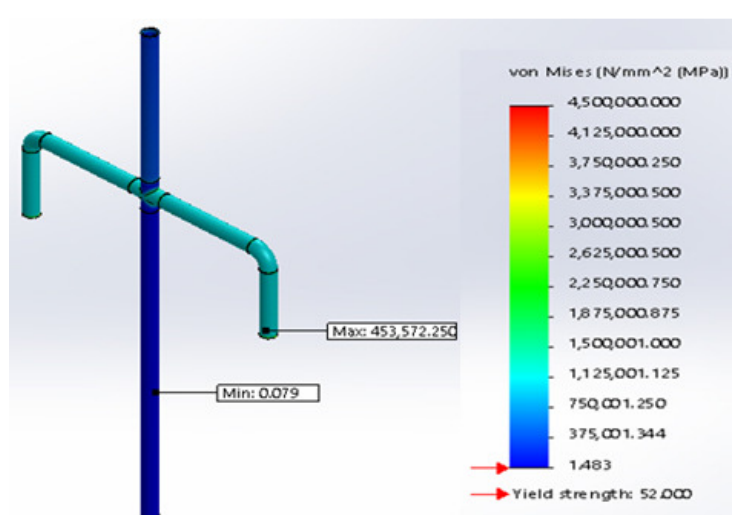

Fig. 6: Von Mises Yield
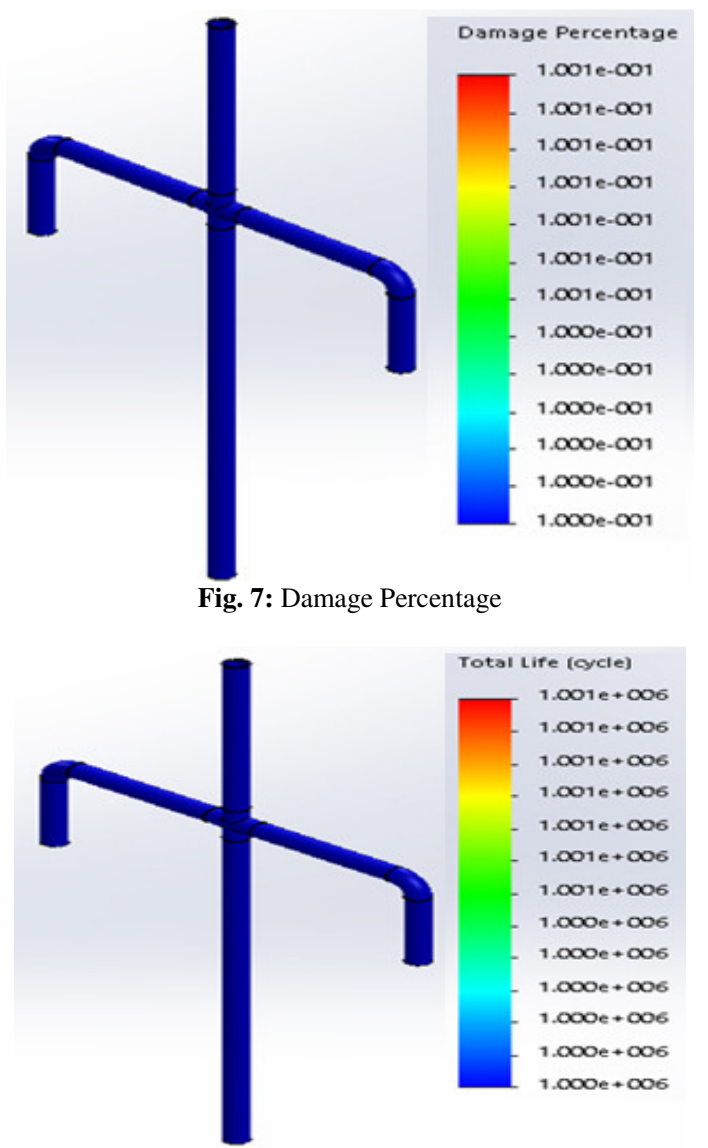

Fig. 8: Total Life Cycle

Conclusion: The results obtained from this research work showed that variation in pressure within the landfill system resulted from the movement of gases from a region of high pressure to regions of low pressure. Therefore, accumulation of gases in a landfill system can create domains for high pressure build-ups where gas migration is impeded by compacted waste stream or landfill covers, and areas of low pressure in which gas flow is not restricted, thereby causing the movement of gases from areas of high gas concentrations to areas with lower gas concentrations.

\section{REFERENCES}

Adewumi, I.; Ogedengbe, M.; Adepetu, J.; and Fabiyi, Y. (2005). Planning Organic Fertilizer Industries for Municipal Solid Waste Management. J. Appl. Sci. Research, 1 (3): 285-291

Akdeniz, F; Caglar A; Gullu, D (2002). Recent energy investigations on fossil and alternative non fossil resources in Turke. Energy Convers. Manage. 43:575-589

Aluko, O.; Sridhar, M.; and Oluwande, P. (2003). Characterization of leachates from a municipal solid waste landfill site in Ibadan, Nigeria. Chart. Insti. of Environ. Health, 2(1)

Arnold, M. (2009). Reduction and monitoring of biogas trace compounds. Publishers: VTT, Vuorimiehentie 3, PL 1000, 02044 VTT and VTT, Bergsmansvagen 3, PB 1000, 02044 VTT, Finland.

Bear, J. (1972). Dynamics of fluids in porous media. American Elsevier Pub. Company

Durmusoglu, E.; Corapcioglu, M. Y.; Asce, F.; and Tuncay, K. (2005). Landfill Settlement with Decomposition and Gas Generation. Journal of Environmental Engineering, 131(9): 1311-1321

Durmusoglu E. (2002). Municipal landfill settlement with refuse decomposition and gas generation. PhD dissertation, Texas A\&M Univ., College Station

Jaramillo, J. (2003). Guidelines for the Design, Construction and Operation of Manual Sanitary Landfills. University of Antioquia, Colombia, Pan American Centre for Sanitary Eng. and Environ. Sci.

Komolafe, T. (2015). Beyond a Dumpsite. Available from<http://hallmarknews.com 
/olusosun-beyond-a-dumpsite/> (27 December 2015)

Lijun, Z.; Jiancheng, S.; Chuanyang, Li.; Yunguang, G.; Pulong, G.; Binni, Q.; Linyan, Lin (2014). Preferential policies promote municipal solid waste (MSW) to energy in China: Current status and prospects. J. of Renew. Sust. Ener. Reviews, 36: 135-148

Ogwueleka, C. (2009). Municipal solid waste characteristics and management in Nigeria. Iranian J. of Environ. Health Sci. Eng., 6(3): 173180

Olmedo, C.; Gomez, A.; and Cartagena, R. (2014). Energetic performance of landfill and digester biogas in a domestic cooker. J. of Appl. Ener. 134: 301-308

Orhorhoro, E.K..; Ebunilo, P.O.; Tamuno, R.I.; and Essienubong, A.I. (2016). The Study of Anaerobic Co-Digestion of Non-Uniform Multiple Feed Stock Availability and Composition in Nigeria. Euro. J. of Eng. Res. and Sci., 1(1): 39-42

Orhorhoro, E.K..; Ebunilo, P.O.; and Sadjere, E.G. (2017). Determination and Quantification of Household Solid Waste Generation for Planning Suitable Sustainable Waste Management in Nigeria. Int. J. of Emerg. Eng. Res. and Tech., 5(8):1-9

Orhorhoro, E.K..; Orhorhoro, O.W.; and Atumah, E.V. (2018). Performance Evaluation of Design AD System Biogas Purification Filter. Int. J. of Math. Eng. and Manag. Sci., 3(1):17-27
Rawson, M.; Sethi, P.; Spiegel, L.; Hope, L; and Oglesby, R. (2012). Removal of Siloxane and $\mathrm{H}_{2} \mathrm{~S}$ from Biogas using Microwave Energy. Sacramento Municipal Utility District, North California, California Energy Commission.

Seadi, T.; Rutz, D.; Prassl, H.; Kottner, M.; Finsterwalder, T.; Volk, S.; and Janssen, R. (2008). Biogas Handbook. Publisher: University of Southern Denmark Esbjerg, Niels Bohrs Vej 910, DK-6700 Esbjerg, Denmark

Teixeira, S.; Monteiro, E.; Silva, V.; and Rouboa, A. (2014). Prospective application of municipal solid wastes for energy production in Portugal. $J$. of Ener. Pol., 71: 159-168

Telekes, G.; Imre, E.; Witt, K. J.; and Ramke, H.G. (2009). Proceedings of the 1st Middle European Conference on Landfill Technology February 6-8, 2008, Budapest, Hungary Szent Istvan University, Budapest, Hungary

Tester, J. F.; Drake, E. M.; Driscoll, M. J.; Golay, M. W.; and Peters W. A. (2005). Sustainable EnergyChoosing Among Option. PHI Learning Private Limited, New Delhi-110001

Ukwaba, S.I.; Ikpe, A.E.; and Orhorhoro, E.K. (2018). Adoption of a Landfill System in Nigeria and the Role of Municipal Solid Waste Segregation on its Performance. Nigerian Res. J. of Eng. and Envirn. Sci., 3(1): 280-286

World Population Review (2015) Nigeria Population 2014. Available from $<$ http://worldpopulationreview.com/countries/nig eria-population/ (26 December 2015 